University of Missouri-Kansas City School of Law

UMKC School of Law Institutional Repository

\title{
The Prescription Drug Pricing Moment: Using Public Health Analysis to Clarify the Fair Competition Debate on Prescription Drug Pricing and Consumer Welfare
}

Ann Marie Marciarille

University of Missouri - Kansas City, School of Law

Follow this and additional works at: https://irlaw.umkc.edu/faculty_works

Part of the Health Law and Policy Commons

\section{Recommended Citation}

Marciarille, Ann Marie, The Prescription Drug Pricing Moment: Using Public Health Analysis to Clarify the Fair Competition Debate on Prescription Drug Pricing and Consumer Welfare (April 27, 2017). The J. L., Med. \& Ethics, 45 S1 (2017): 45-49., Available at SSRN: https://ssrn.com/abstract=2959466 


\title{
The Prescription Drug Pricing Moment: Using Public Health Analysis to Clarify the Fair Competition Debate on Prescription Drug Pricing and Consumer Welfare
}

\author{
Ann Marie Marciarille
}

\section{Introduction}

The American Public Health Association tells us that "[p]ublic health promotes and protects the health of people and the communities where they live, learn, work and play." It further distinguishes public health concerns from clinical health concerns by the latter's focus on the individual's special circumstances. When it comes to prescription drug cost and access, both the health of the community and the health of the individual may be implicated. Even individual prescription drug access has a collective element, in that we do not typically purchase or acquire prescription pharmaceuticals as individuals until the very last stage of distribution: retail sale. Rather, the journey of a prescription drug from manufacturer to individual consumer occurs in stages, most of them highly intermediated by collective contracting by a pharmacy benefit manager or by the government before the pharmaceutical reaches the level of retail distribution. This pre-retail sale collective phase of pharmaceutical acquisition and distribution has direct and serious implications for pharmaceutical cost and access for all.

In pharmaceutical pricing and distribution we find ourselves at the intersection of collective and individual health concerns in the United States. The recent price spikes in pharmaceuticals present problems of access and affordability that rise to the level of a public health challenge. Because we consume pharmaceutical drugs individually according to our unique health profiles, we experience problems of cost and access individually. Nevertheless, pricing and its attendant access and affordability concerns are at the intersection of two important values that have always been

Ann Marie Marciarille, J.D., is a Professor of Law at the University of Missouri at Kansas City. central to public health: community health and individual responsibility.

\section{Antitrust}

American antitrust law has its own analytical axis on which to examine the organization of pharmaceutical manufacturing firms and the structure of their industry. This axis is found in the debate over the definition of consumer welfare. Antitrust considers one definition or calculus of consumer welfare that includes savings that do not redound to the pharmaceutical consuming public directly and also considers a second that excludes those savings that do not redound directly to the pharmaceutical consuming public.

Professor Stephen Salop, for example, offers a vision of consumer welfare that resonates with public health analysis. He argues that a "true consumer welfare standard would condemn conduct [that] reduces the welfare of buyers, irrespective of its impact on sellers." ${ }^{3}$ He argues that efficiencies that redound elsewhere should only be found relevant to this calculus if such efficiencies are eventually passed through to consumers. ${ }^{4}$ Antitrust analysis also offers a competing definition of consumer welfare, one that values efficiencies that are not necessarily passed through to the pharmaceutical consuming public but, rather, retained by the pharmaceutical firm for the research and development of new products or returned to its shareholders and investors. ${ }^{5}$

Thus, fair competition law and public health law talk past each other when discussing pharmaceutical pricing and distribution. The former cannot agree on the relevant definition of consumer welfare. The latter does not fully comprehend the highly complex but inherently collective nature of pharmaceutical drug acquisition in the United States. 
What might public health analysis contribute to the current roiling debate ${ }^{6}$ over pharmaceutical pricing and, in particular, about solutions consistent with American values? This essay proposes to inject public health discourse into this debate to enrich it, focus it, and render it more accessible to those who must live by its outcome. As David Blumenthal and David Squires have pointed out, drug pricing is having its moment, ${ }^{7}$ and this attentive moment is long overdue.

\section{Understanding Our Collective Acquisition of Pharmaceutical Drugs}

It is a truism of American pharmaceuticals that what you pay is determined by who you are. Such price discrimination ${ }^{8}$ is embedded in the American health care landscape of multiple overlapping health care systems, each designed to serve different populations and each designed to cross-subsidize cost and access to pharmaceuticals for some by others.

The history of our systems of pharmaceutical pricing is astonishingly complex. A few lessons may be gleaned from its origins in our multi-layered combining of different health care systems onto each other. Our pharmaceutical pricing regimes can be seen as the fullest flowering of our commitment to three principles: free market rewards for innovation, our commitment to prioritized preferential access to pharmaceutical drugs for certain populations, and our comfort with market-governed exclusion from access to certain pharmaceutical drugs for other populations. Seen in this light, the tradition of the Veterans Administration in - for example - leading the way as the low price leader, by custom and by statute, on domestic pharmaceutical acquisition cost, is the modern version of Abraham Lincoln's motivation in founding the Veteran's Administration in 1865, “...to care for him who shall have borne the battle, and for his widow, and his orphan."9 By extension, all modern government programs that benefit favored groups with preferential cost and access to prescription drugs - whether it be veterans, or the "deserving poor" in non-Medicaid expansion states, or some lower-income individuals in Medicaid expansion states - have a connection to this history of favored pricing for their group.

While it is fascinating to consider the rationale for favored-group pricing for pharmaceuticals, it is as important to consider who is not in that category. In the modern era, it is most particularly Medicare beneficiaries. ${ }^{10}$ The "why not" here may be the most significant story to tell.

Direct price negotiation for pharmaceuticals has never been a consistent enduring part of the Medicare program..${ }^{11}$ Medicare's exclusion from the groups of the insured that are allowed to bargain to reduce pharma- ceutical drug acquisition cost as a tool for improving prescription drug access and affordability, is the direct result of representations made and deals struck to ensure pharmaceutical industry non-opposition both to the Medicare Modernization Act in $2003^{12}$ and to the Affordable Care Act in 2010.13 Thus low and lower income Medicare beneficiaries are at the mercy of the market (in Part B infusion therapies used to combat cancer, for example), and (in Part D) at the mercy of the negotiating power of their insurer and their insurer's pharmacy benefit manager - if they can afford to get themselves inside this tent.

Medicare Part C, sometimes called Medicare Managed Care, is commercial insurance sold through a structured marketplace where the insurers may engage in direct bargaining for pharmaceuticals. Medicare beneficiaries who are not poor enough to be eligible for Medicaid but who are not rich enough to purchase a robust Part D plan make up a significant portion of the Medicare Part $\mathrm{C}$ enrollment population. ${ }^{14}$ The non-trivial public health concerns raised by elders who sacrifice all to pay their Part B premiums, Part D premiums, and Medicare Supplemental Insurance for fear of tightly managed care are sobering. The love of narrow networks and tightly constrained formularies is not strong in the Medicare population, making Part $\mathrm{C}$ enrollment a last resort for many so enrolled. ${ }^{15}$

On the commercial insurance side, we can also see direct bargaining but with fractured buyer power. Perverse incentives are generated by pharmacies' and pharmacy benefit managers' (PBMs) working off of a business model based on a percentage of cost and price along with dispensing fees. These lessen the likelihood that commercial insurers, PBMs, or commercial pharmacies will rise to full-throated discussion of the effects of pharmaceutical pricing and distribution systems on cost and access for individuals.

Different solutions are likely appropriate for different problems in different segments of the pharmaceutical market. As Rena M. Conti has pointed out, ${ }^{16}$ the problem of price spikes in generic drugs, where the government can do so much more to entice generic drug manufacturers into the marketplace, is undoubtedly different from credible solutions to the price spike in branded drugs first to market with true innovation. This problem is also different from any credible solution to price spikes in pharmaceuticals that, however new to the market, are being sold into a drug universe where there are other therapeutic equivalents available at radically different price points.

In this last group, experiments with different forms of reference pricing or grouping drugs into categories based on therapeutic effect and moving only those drugs that have a distinctive therapeutic effect into 
higher priced categories, have gained some traction in other countries and in commercial insurance in the United States. More politically palatable and thereby perhaps more possible than government price setting, reference pricing merits further consideration. It attempts to balance the welfare of the group in promoting pharmaceutical innovation with the interest of the group in promoting affordability and access. Public health analyses weighing these two competing values can enrich the conversation. Reference pricing attempts to thread the needle between reasonable reward of innovation and unreasonable restrictions on access.

\section{Considering Daraprim}

Turing Pharmaceuticals' (Turing) Daraprim (pyrimethamine) frames the issue of how to address the $5,000 \%$ price increase of a decades-old drug most widely known for the treatment of toxoplasmosis. Daraprim is a sole source drug. Turing's price increases of sole-source market position produced a product unavailable to many who lacked insurance or were under-insured.

Important work has been done by Michael A. Carrier, Nicole Levidow, and Aaron S. Kesselheim on the antitrust implications of Daraprim production and distribution. ${ }^{17}$ Turing's behavior around Daraprim may give rise to a monopolization claim with a focus on the changes made to the drug's distribution system to keep rivals from entering the generic market with a competitor product. ${ }^{18}$ More interesting, for the purposes of this essay, is whether either the Daraprim price increase itself or the exclusionary re-configured distribution system can be said to harm public health and consumer welfare.

Daraprim has been eligible for generic development for close to 50 years. No generic had entered this market. It illustrates that the cost of a modestly valued drug may be substantially enhanced by a drug distribution mechanism that defeats generic

As a public health matter, the FDA has announced its intention to prioritize generic drug applications on sole-source drugs. What is lacking in public discussion is mention of the public health implications of rendering a curative sole source drug unaffordable to those with no other option. The discussion, instead, is cast as an individual's problem of cost and ccess. Lacking a vocabulary for the kind of harm we all suffer when a therapeutic alternative is effectively removed because of its extraordinary acquisition cost, antitrust law can learn from public health that the consumer welfare on prescription drug pricing in the United States is collective.

were accompanied by a re-design of Daraprim's distribution system to a single distributor: Walgreen's. The drug was little known because of the relative rarity of its use. The story of how it became so lucrative to its manufacturer can be read as the story of a sole-source supplier and supply limited to a distribution network that essentially worked to constrict supply to those seeking to investigate development of a generic bioequivalent. The product was deemed by many to be without significant value or potential for significant return on investment. This offers, at the very least, a compelling story of how to maximize return. It also offers an opportunity to stop and consider how our goals are balanced betweeen reward of innovation and production of therapeutic products for public use. Daraprim's scenario gives pause. There was no substantial biochemical innovation. The gaming entry. Daraprim reminds us that the general rule that increased competition will discipline sudden price spikes depends on that new entry being "timely, likely, and sufficient." 19 Turing's re-priced Daraprim and reconfigured Daraprim distribution system has already existed long enough to have made the changes highly profitable. Indeed, a competing generic entry, at this point, could hardly be said to be timely from the perspective of drug costs. Many millions of dollars have been wrung out of the drug acquisition system on an overnight price spike. ${ }^{20}$

A crucial variable in promoting competition for generic eligible pharmaceuticals is supposed to be to keep the opportunities for generic entrants open. ${ }^{21}$ Federal Trade Commission (FTC) data tells us that the more generic entrants, the more price competition, ${ }^{22}$ at least to a point. None of this contemplates a 
sole source price spike combined with a distribution mechanism designed to delay generic entry to make new entry untimely. If such exclusionary behavior is not to prove both lucrative and replicable, antitrust law needs a different definition of timely entry. And it may also need a more focused definition of consumer welfare to talk back to distribution system innovation designed to suppress competition.

Public health can help antitrust law find this vocabulary and legal analysis. Turing's innovation was in learning how to game the generic entrant system to delay or divert new entrants for an expensive interval. Antitrust law will need to determine if this is the kind of innovation that brings efficiencies. As a public health matter, the FDA has announced its intention to prioritize generic drug applications on sole-source drugs. ${ }^{23}$ What is lacking in public discussion is mention of the public health implications of rendering a curative sole source drug unaffordable to those with no other option. The discussion, instead, is cast as an individual's problem of cost and ccess. Lacking a vocabulary for the kind of harm we all suffer when a therapeutic alternative is effectively removed because of its extraordinary acquisition cost, antitrust law can learn from public health that the consumer welfare on prescription drug pricing in the United States is collective.

\section{Conclusion}

Public health's recognition of collective as well as individual interests in affordability and access offers a vocabulary that fair competition law might be able to use. It could power a consumer welfare analysis of market gaming behavior that extends beyond shifting pharmaceutical acquisitions costs to other payers and, in fact, effectively sets public health priorities. The reality is that our pharmaceutical drug budget is not infinite. Elevated prices for some pharmaceuticals thus reduce access to other pharmaceuticals for everyone.

\section{Acknowledgment}

Thanks to Valerie Shea for her fine research assistance.

\section{References}

1. American Public Health Association, "What Is Public Health?" available at <https://www.apha.org/what-is-public-health> (last visited January 20, 2017).

2. S. C. Salop, "Question: What Is the Real and Proper Antitrust Welfare Standard? Answer: The True Consumer Welfare Standard," Loyola Consumer Law Review 22, no. 3 (2010): 336353, at 336, available at <http://lawecommons.luc.edu/cgi/ viewcontent.cgi? article $=1061 \&$ context=lclr $>$ (last visited January 20, 2017)

3. Id., at 336-37.

4. See K. Heyer, Welfare Standards and Merger Analysis: Why Not the Best?, Economic Analysis Group Discussion Paper, March 2006, available at <https://www.justice.gov/sites/ default/files/atr/legacy/2007/09/28/221880.pdf> (last visited
January 20, 2017) (arguing for "a total welfare standard - i.e., a standard that considers a merger's likely effect on all members of society, not simply the consumers of products produced by the merging firms.").

5. It is not every issue that, in one week, focused both congressional concern and focused popular cultural concern. Congressional concern as expressed by the call for Committee hearings on and inquiry into the pricing of certain pharmaceuticals. See A. Edney, "Mylan CEO to be Grilled by Congress Over EpiPen Price Surge," Bloomberg Politics, September 14, 2016, available at <https://www.bloomberg.com/politics/articles/2016-09-14/ mylan-ceo-will-appear-before-house-oversight-panel-nextweek> (last visited January 20, 2017). Popular cultural concern was expressed by the knowing laugh at the 2016 Emmy Awards broadcast when Jimmy Kimmel, the program's host, noted, while passing out brown bags stuffed with peanut butter and jelly sandwiches, "If you're allergic to peanuts, well, I guess this is goodbye, because we can only afford one EpiPen." See S. Rense, "The Story Behind Jimmy Kimmel's Sharpest Joke at the Emmys," Esquire, September 19, 2016, available at <http://www.esquire.com/lifestyle/health/videos/a48703/ epipen- joke-emmys-transparent/> (last visited January 20, 2017); see also K. Don, "Jimmy Kimmel's EpiPen Joke at the 2016 Emmys Was Honestly Very Much Appreciated," Romper, available at <https://www.romper.com/p/jimmy-kimmelsepipen-joke-at-the-2016-emmys-was- honestly-very-muchappreciated-18614> (last visited January 20, 2017) (observing that " $[\mathrm{n}]$ ot only was [the EpiPen] joke incredibly well-timed, but it was also well received by the audience.").

6. D. Blumenthal and D. Squires, "Drug Price Control: How Some Government Programs Do It," Commonwealth Fund, May 10, 2016, available at <http://www.commonwealthfund.org/publications/ blog/2016/may/drug-price-control-how-some-governmentprograms-do-it> (last visited January 20, 2017).

7. Price discrimination is selling the same good at different prices to different customers. See E. R. Berndt and J. P. Newhouse, "Pricing and Reimbursement in the US Pharmaceutical Markets," in P. M. Danzon and S. Nicholson, eds., Oxford Handbook of the Economics of the Biopharmaceutical Industry (Oxford University Press, 2012): at 201, 233.

8. A. Lincoln, "Second Inaugural Address," March 4, 1865, available at <https://memory.loc.gov/cgi-bin/query/r?ammem/ mal:@field(DOCID+@lit(d4361300))> (last visited January 20, 2017); see J. W. Mapp, Civil War: The Origins of Veterans Health Care, U.S. Department of Veterans Affairs, available at <http://www.va.gov/health/NewsFeatures/20110413a.asp> (last visited January 20, 2017)

10. Both Part B pharmaceutical coverage and Part D prescription drug plans encompass Medicare beneficiaries at all income levels.

11. Medicare's brief experiment with the Least Costly Alternative (LCA) policy marks its most recent foray into a type of reference pricing, an experiment abruptly terminated by litigation in December 2009. See R. M. Conti and M. B. Rosenthal, "Pharmaceutical Policy Reform - Balancing Affordability with Incentives for Innovation," Nere England Journal of Medicine 374 (2016): 703-706, at 705; see also Hays v. Leavitt, 583 F. Supp. 2d 62 (D.D.C. 2008), aff'd sub nom. Hays v. Sebelius, 589 F.3d 1279 (D.C. Cir. 2009) (ruling the LCA Policy as inconsistent with the Medicare statute); see also Medicare Payment Advisory Commission, Report to Congress: Medicare and the Health Care Delivery System, MedPac 88 (June 2015), available at <http://www.medpac.gov/docs/default-source/reports/ june-2015-report-to-the-congress-medicare-and-the-healthcare-delivery-system.pdf?sfvrsn $=0>$ (last visited January 20, 2017) (reporting Congress would need to grant that statutory authority to the Secretary of Health and Human Services in order for LCA to be tried again).

12. Medicare Prescription Drug, Improvement, and Modernization Act of 2003, Pub. L. No. 108-173, 117 Stat. 2066 (amending Title XVIII of the Social Security Act). 
13. Patient Protection and Affordable Care Act, 42 U.S.C. $§ 18001$ (2010).

14. See A. M. Marciarille, "Go Ask Alice," Missouri State of Mind (January 19, 2013), available at <http://www.marciarille. com/2013/01/go-ask-alice.html> (last visited January 20, 2017) (discussing how Medicare beneficiaries end up in Medicare Part C).

15. See Medicare Prescription Drug, Improvement, and Modernization Act of 2003, Pub. L. No. 108-173, 117 Stat. 2066 (amending Title XVIII of the Social Security Act).

16. See Conti and Rosenthal, supra note 11, at 704 .

17. M. A. Carrier, N. Levidow, and A. S. Kesselheim, "Using Antitrust Law to Challenge Turing's Daraprim Price Increase," Berkeley Technology Law Journal 31 (2016).

18. Id.

19. Federal Trade Comm'n v. Cardinal Health, Inc., 12 F.Supp.2d 34, 55 (D.D.C.1998) citing U.S. Dep't. of Justice \& Federal Trade Comm'n, Horizontal Merger Guidelines Section 3.0 (1992).

20. See A. Pollack, "Drug Goes from $\$ 13.50$ to a Tablet to $\$ 750$, Overnight," New York Times, September 20, 2015, available at <http://www.nytimes.com/2015/09/21/business/a-huge-overnight-increase-in-a-drugs-price-raises-protests.html > (last visited January 20, 2017).

21. See L. M. Olson and B. W. Wendling, Effect of Generic Drug Competition on Generic Drug Prices During the Hatch-Waxman 180-Day Exclusivity Period (F.T.C. Bureau of Econ., Working Paper No. 317, 2013), available at <https://www.ftc. gov/sites/default/files/documents/reports/estimating-effectentry-generic-drug-prices-using-hatch-waxman-exclusivity/ wp317.pdf> (last visited January 20, 2017).

22. $I d$

23. See Z. Brennan, "FDA to Prioritize Generic Drug Applications for 'Sole Source' Products," Regulatory Affairs. Professionals Society, March 14, 2016, available at <http://raps. org/Regulatory-Focus/News/2016/03/14/24532/FDA-toPrioritize-Generic-Drug-Applications-for- $\% \mathrm{E} \% 80 \% 98$ SoleSource $\%$ E2\% 80\%99-Products/> (last visited January 20, 2017). 